\title{
Impact of the routine varicella vaccination programme on varicella epidemiology in Germany
}

A Siedler (SiedlerA@rki.de) ${ }^{1}$, U Arndt ${ }^{2}$

1. Department of Infectious Disease Epidemiology, Robert Koch Institute, Berlin, Germany

2. German Green Cross, Marburg, Germany

Citation style for this article: Siedler A, Arndt U. Impact of the routine varicella vaccination programme on varicella epidemiology in Germany. Euro Surveill. 2010;15(13): pii=19530. Available online: http://www.eurosurveillance.org/ViewArticle.aspx?Articleld=19530

This article has been published on 1 April 2010

Routine varicella vaccination with one dose for children of 11 to 14 months was recommended in Germany in 2004 to reduce disease incidence and severe complications. A country-wide varicella sentinel surveillance system was initiated in 2005 to detect trends of disease frequency and vaccine uptake and to evaluate the vaccination programme. A convenient sample of about 1,000 paediatricians and general practitioners was recruited to report on a monthly basis on varicella cases by age groups seen in their practice, and on varicella vaccine doses administered. Sentinel data from April 2005 to March 2009 show a reduction of $55 \%$ of varicella cases in all ages; $63 \%$ in the age group $0-4$ years and $38 \%$ in $5-9$ year-olds. The number of vaccine doses per reporting unit in all regions and physician groups increased during the same period. The number of reported cases as well as administered vaccines differed between physician groups and regions with different reimbursement policies. Where reimbursement was settled early and vaccine doses were increasing varicella cases started to decrease early as well. Besides reimbursement policies the availability and vaccination schedules influenced vaccine uptake. Sentinel surveillance provided valid data on trends for varicella associated morbidity, vaccine uptake and the age distribution of cases. The results confirm that following the introduction of routine varicella vaccination, varicella morbidity started to decline in Germany.

\section{Introduction}

Varicella vaccination was introduced for all children older than 11 months in July 2004 in Germany [1]. Besides the age group (11-14 months) for which vaccination was recommended, closing of individual immunisation gaps was generally recommended for all children and adolescents below 18 years of age. However, no systematic catch-up vaccination was foreseen.

The main aim of the routine varicella vaccination programme is the reduction of the burden of disease and of varicella related complications. However, this was not quantified [2]. Experiences from the United States (US), where varicella vaccination was introduced in the vaccination schedule already in 1996 [3,4], along with new data on the burden of disease [5] have influenced the decision to introduce varicella vaccination in Germany. Recommendations include defined antigens but not specific vaccines. All available licensed vaccines can be used according to the official information provided by the manufacturer. At the time when the recommendation was issued, two monovalent varicella vaccines were available for the administration of one dose in early childhood and two doses in children over 13 years of age. However, the costs for varicella vaccination were not covered by health insurances in all German federal states when varicella vaccination was recommended. Negotiations on reimbursement were successfully settled in spring 2006 for all states. In summer 2006, a combined vaccine against measles, mumps, rubella and varicella (MMRV) was licensed with a two-dose schedule and in 2008 licensures for the two monovalent vaccines were changed to twodose schedules for all ages. In July 2009 the recommendation was changed to a two-dose schedule, with the second dose recommended at 15 to 23 months of age and with a minimum time interval of four to six weeks after the first dose. Thus, children in Germany have been vaccinated with different vaccines and different schedules since 2004 .

Paediatricians have a key role in the immunisation of children as well as in their healthcare (including diagnosis and treatment) in Germany. Ninety-five per cent of children see a paediatrician within the first two years of life [6]. This percentage decreases with increasing age to $25 \%$ for $14-17$ year-olds and general practitioners (GPs) treat up to $53 \%$ of the adolescents [6]. Therefore these two physician groups seem to be most appropriate for monitoring varicella disease and varicella vaccination. Varicella is not a notifiable disease in Germany. Therefore a country-wide varicella sentinel surveillance system was implemented in April 2005 in order to detect trends of disease frequency and vaccine uptake and to monitor the impact and the acceptance of the varicella vaccination programme.

This report reflects first results of the sentinel surveillance and describes the association between vaccine 
uptake and frequency of varicella cases after introduction of routine varicella vaccination as well as factors influencing the vaccine uptake.

\section{Methods}

Sentinel surveillance

The country-wide sentinel project on varicella and zoster epidemiology is managed in public-private-partnership by the German national public health institute, the Robert Koch Institute (RKI) which is responsible for the scientific management and, the German Green Cross (DGK), responsible for the recruitment of physicians and data management. The vaccine manufactures GlaxoSmithKline and Sanofi Pasteur MSD are financing the work at DGK, the RKI receives no financial support from the manufacturers. An independent scientific board gives scientific and operational advice for running the surveillance system. The system is called "working group on measles and varicella" (Arbeitsgemeinschaft Masern und Varizellen, AGMV) [7].

A convenient sample of over 1,000 primary care physicians was recruited, consisting of $60 \%$ paediatricians and $40 \%$ GPs and accounting for about $15 \%$ of all German paediatricians and about $1 \%$ of all GPs in practice. Sentinel physicians of both groups are distributed across all 16 German federal states equally to the distribution of respective physicians in practice. Physicians participate on voluntary basis and neither doctors nor patients receive incentives. As patients are free to choose and change their physician and only a subset of physicians report to the sentinel, the population size under surveillance can not be defined. The sentinel is not population based and does aim at trends but not at incidence.

Physicians provide aggregated numbers of varicella cases by age groups through monthly questionnaires. Age groups are divided as follows: «1 year, 1-4 years, 5-9 years, 10-14 years, 20 years and older. Doctors document the number of patients with varicella complications, vaccinated varicella cases and cases of herpes zoster. In addition, they report the monthly number of administered doses of varicella vaccines by first and second doses and since April 2007 doses are divided into monovalent and combined varicella vaccines. Zero-reporting and active reminders are included and the questionnaire provides case definitions. A case of varicella is defined as a person presenting at the physician's practice with a clinical picture resembling varicella, with skin exanthema and concomitant presentation of papules, blisters, pustules, crusts. Varicella complications are defined as varicella leading to hospitalisation, oral or parenteral antibiotic or antiviral therapy or as accompanied by neurological symptoms. Vaccinated varicella cases are persons vaccinated against varicella regardless of the time interval between vaccination and onset of varicella. Herpes zoster is defined as appearance of blisters on an exanthematic skin, confined to a spinal or cranial nerve pathway, accompanied by at least one out of the following symptoms: painful neuralgia of the affected region, fever, loss of appetite, myalgia, burning sensation

\section{FIGURE 1}

Number of varicella cases and reporting units by physician group, sentinel data, Germany, April 2005-March 2009

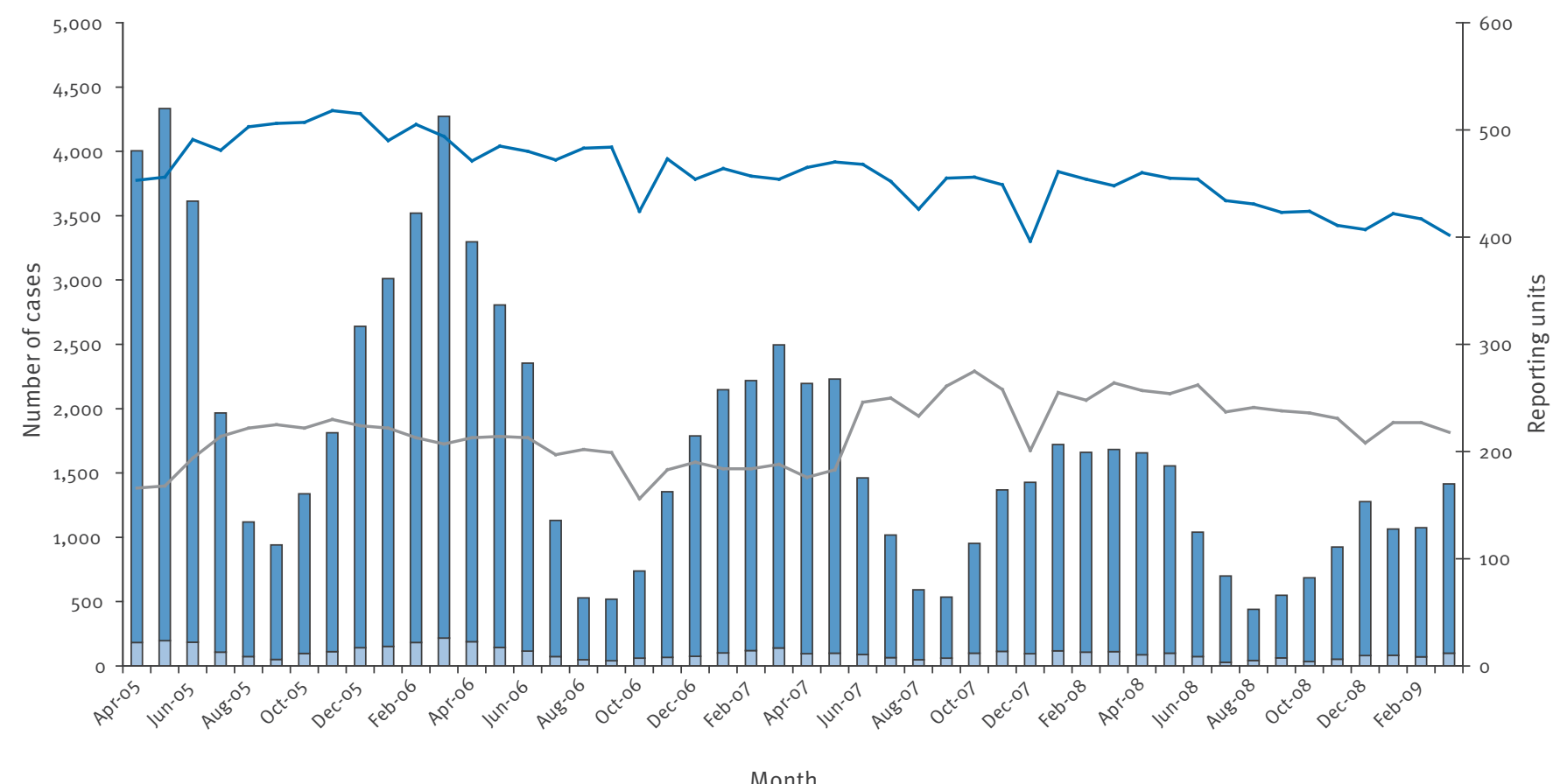

$\square$ Cases by general practitioners — Reporting general practitioners $\square$ Cases by paediatricians

- Reporting paediatricians 
and/or itching of the affected region. Physicians are asked to report the number of patients they have seen at their practice in the respective month and categories. Laboratory confirmation is not required.

\section{Descriptive Analysis}

Data on varicella cases per age group and on varicella vaccinations by first and second doses were analysed and available from April 2005 to March 2009. Defining a varicella season as lasting from April until March of the following year, the surveillance covered four complete varicella seasons (2005-6, 2006-7, 2007-8, 20089). The number of reported varicella cases as well as the number of vaccine doses was related to the number of reporting physicians (units) as denominator in the respective month or season. Reporting physicians were grouped by speciality (paediatricians/GPs) and by region. Three regions were formed according to reimbursement policies (i) region 1: vaccination costs covered since general recommendation (cost regulations completed before 2005-6 season); (ii) region 2: reimbursement settled in 2005 (regulations completed during 2005-6 season) and (iii) region 3: reimbursement settled in 2006 and partly restricted for specific age or vaccine only until March 2007 (regulations completed during 2006-7 season).

For data entry and data management MS Office ACCESS version 2003 was used, descriptive data analysis was carried out by SPSS version 16 .

\section{Results \\ Varicella cases, vaccinations, reporting units over time}

From April 2005 (start of season 1) until March 2009 (end of season 4), a total of 83,181 varicella cases were reported by 1,178 physicians. During the same time 289,327 first and 86,394 second doses of varicella vaccine were administered by sentinel physicians.

Seasonal peaks of varicella disease occurred in spring. The peaks flattened over time, whereas the total number of reporting physicians remained fairly stable. A slight decrease in the number of reporting paediatricians was balanced by an increase in the number of GPs (Figure 1). Paediatricians formed the majority of

\section{TABLE 1}

Mean number of varicella vaccines and varicella cases per reporting unit and month by physician group and cost cover region over four consecutive varicella seasons, sentinel data, Germany, April 2005-March 2009

\begin{tabular}{|c|c|c|c|c|c|c|c|c|c|}
\hline \multirow[b]{2}{*}{$\begin{array}{l}\text { Physician } \\
\text { group }\end{array}$} & \multirow[b]{2}{*}{$\begin{array}{l}\text { Season }^{1} \\
\text { (units) }\end{array}$} & \multicolumn{2}{|c|}{$\begin{array}{l}\text { Region 1: cost regulations } \\
\text { before season } 2005^{-6}\end{array}$} & \multicolumn{2}{|c|}{$\begin{array}{l}\text { Region 2: cost regulations } \\
\text { in season } 2005-6\end{array}$} & \multicolumn{2}{|c|}{$\begin{array}{l}\text { Region 3: cost regulations } \\
\text { in season } 2006-7\end{array}$} & \multicolumn{2}{|c|}{ All regions together } \\
\hline & & $\begin{array}{c}\text { Vaccines } \\
\text { per unit and } \\
\text { month } \\
(95 \% \mathrm{Cl})\end{array}$ & $\begin{array}{l}\text { Cases per } \\
\text { unit and } \\
\text { month } \\
(95 \% \mathrm{CI})\end{array}$ & $\begin{array}{c}\text { Vaccines } \\
\text { per unit and } \\
\text { month } \\
(95 \% \mathrm{Cl})\end{array}$ & $\begin{array}{l}\text { Cases per } \\
\text { unit and } \\
\text { month } \\
(95 \% \mathrm{CI})\end{array}$ & $\begin{array}{c}\text { Vaccines } \\
\text { per unit and } \\
\text { month } \\
(95 \% \mathrm{Cl})\end{array}$ & $\begin{array}{l}\text { Cases per } \\
\text { unit and } \\
\text { month } \\
(95 \% \mathrm{Cl})\end{array}$ & $\begin{array}{c}\text { Vaccines } \\
\text { per unit and } \\
\text { month } \\
(95 \% \mathrm{Cl})\end{array}$ & $\begin{array}{l}\text { Cases per } \\
\text { unit and } \\
\text { month } \\
(95 \% \mathrm{Cl})\end{array}$ \\
\hline \multirow{4}{*}{$\begin{array}{l}\text { Paediatric } \\
\text { reporting } \\
\text { units }\end{array}$} & $\begin{array}{l}2005-6 \\
(N=635)\end{array}$ & $\begin{array}{c}13.76 \\
(12.52-14.99) \\
\end{array}$ & $\begin{array}{c}3.72 \\
(2.46-4.99) \\
\end{array}$ & $\begin{array}{c}13.41 \\
(11.44-15.37) \\
\end{array}$ & $\begin{array}{c}5.54 \\
(3.74-7.35) \\
\end{array}$ & $\begin{array}{c}6.63 \\
(5.15-8.12) \\
\end{array}$ & $\begin{array}{c}5.73 \\
(3.99-7.47) \\
\end{array}$ & $\begin{array}{c}11.27 \\
(9.87-12.66) \\
\end{array}$ & $\begin{array}{c}5.00 \\
(4.11-5.89) \\
\end{array}$ \\
\hline & $\begin{array}{l}2006-7 \\
(N=548)\end{array}$ & $\begin{array}{c}15.48 \\
(14.18-16.78)\end{array}$ & $\begin{array}{c}1.99 \\
(1.34-2.64)\end{array}$ & $\begin{array}{c}16.70 \\
\left(15.42^{-}\right. \\
17.98)\end{array}$ & $\begin{array}{c}3.2 \\
(2.14-4.26)\end{array}$ & $\begin{array}{c}13.38 \\
(12.08- \\
14.68) \\
\end{array}$ & $\begin{array}{c}6.03 \\
(3.96-8.10)\end{array}$ & $\begin{array}{c}15.19 \\
(14.37- \\
16.00)\end{array}$ & $\begin{array}{c}3.74 \\
(2.81-4.67)\end{array}$ \\
\hline & $\begin{array}{l}2007-8 \\
(N=530)\end{array}$ & $\begin{array}{c}21.06 \\
(18.86- \\
23.26)\end{array}$ & $\begin{array}{c}1.93 \\
(1.40-2.47)\end{array}$ & $\begin{array}{c}20.49 \\
(19.00- \\
21.99)\end{array}$ & $\begin{array}{c}2.37 \\
(1.84-2.90)\end{array}$ & $\begin{array}{c}14.90 \\
(13.90- \\
15.89) \\
\end{array}$ & $\begin{array}{c}5.03 \\
(3.52-6.54)\end{array}$ & $\begin{array}{c}18.82 \\
(17.54- \\
20.09)\end{array}$ & $\begin{array}{c}3.11 \\
(2.42-3.80)\end{array}$ \\
\hline & $\begin{array}{l}2008-9 \\
(N=499)\end{array}$ & $\begin{array}{c}24.72 \\
(22.87- \\
26.56) \\
\end{array}$ & $\begin{array}{c}1.91 \\
(1.53-2.29)\end{array}$ & $\begin{array}{c}25.50 \\
(23.58- \\
27.42)\end{array}$ & $\begin{array}{c}2.07 \\
(1.56-2.58)\end{array}$ & $\begin{array}{c}20.73 \\
(18.07- \\
23.39)\end{array}$ & $\begin{array}{c}2.98 \\
(2.10-3.86)\end{array}$ & $\begin{array}{l}23.65 \\
(22.32- \\
24.98)\end{array}$ & $\begin{array}{c}2.32 \\
(1.96-2.68)\end{array}$ \\
\hline \multirow{4}{*}{$\begin{array}{l}\text { GP reporting } \\
\text { units }\end{array}$} & $\begin{array}{l}2005-6 \\
(N=323)\end{array}$ & $\begin{array}{c}2.04 \\
(1.53-2.55)\end{array}$ & $\begin{array}{c}0.53 \\
(0.28-0.78)\end{array}$ & $\begin{array}{c}2.09 \\
(0.77-3.41)\end{array}$ & $\begin{array}{c}0.63 \\
(0.44-0.82)\end{array}$ & $\begin{array}{c}1.29 \\
(0.62-1.95)\end{array}$ & $\begin{array}{c}0.92 \\
(0.62-1.23)\end{array}$ & $\begin{array}{c}1.8 \\
(1.32-2.29)\end{array}$ & $\begin{array}{c}0.70 \\
(0.55-0.84)\end{array}$ \\
\hline & $\begin{array}{c}2006-7 \\
(\mathrm{~N}=260)\end{array}$ & $\begin{array}{c}2.92 \\
(2.30-3.55)\end{array}$ & $\begin{array}{c}0.42 \\
(0.29-0.55)\end{array}$ & $\begin{array}{c}2.72 \\
(2.07-3.36)\end{array}$ & $\begin{array}{c}0.38 \\
(0.28-0.48)\end{array}$ & $\begin{array}{c}2.22 \\
(1.89-2.55)\end{array}$ & $\begin{array}{c}0.82 \\
(0.57-1.07)\end{array}$ & $\begin{array}{c}2.62 \\
(2.32-2.92)\end{array}$ & $\begin{array}{c}0.54 \\
(0.43-0.65)\end{array}$ \\
\hline & $\begin{array}{l}2007-8 \\
(\mathrm{~N}=381)\end{array}$ & $\begin{array}{c}2.83 \\
(2.11-3.54) \\
\end{array}$ & $\begin{array}{c}0.21 \\
(0.14-0.28) \\
\end{array}$ & $\begin{array}{c}2.82 \\
(2.28-3.36) \\
\end{array}$ & $\begin{array}{c}0.34 \\
(0.29-0.39) \\
\end{array}$ & $\begin{array}{c}2.43 \\
(2.03-2.84) \\
\end{array}$ & $\begin{array}{c}0.58 \\
(0.42-0.73)\end{array}$ & $\begin{array}{c}2.69 \\
(2.39-2.99) \\
\end{array}$ & $\begin{array}{c}0.37 \\
(0.30-0.45)\end{array}$ \\
\hline & $\begin{array}{l}2008-9 \\
(\mathrm{~N}=330)\end{array}$ & $\begin{array}{c}3.34 \\
(2.82-3.85) \\
\end{array}$ & $\begin{array}{c}0.14 \\
(0.09-0.18) \\
\end{array}$ & $\begin{array}{c}2.81 \\
(2.36-3.27) \\
\end{array}$ & $\begin{array}{c}0.27 \\
(0.21-0.34) \\
\end{array}$ & $\begin{array}{c}2.82 \\
(2.33-3.31) \\
\end{array}$ & $\begin{array}{c}0.37 \\
(0.25-0.50)\end{array}$ & $\begin{array}{c}2.99 \\
(2.73-3.25) \\
\end{array}$ & $\begin{array}{c}0.26 \\
(0.20-0.32)\end{array}$ \\
\hline \multirow{4}{*}{$\begin{array}{l}\text { All reporting } \\
\text { units }\end{array}$} & $\begin{array}{c}2005-6 \\
(\mathrm{~N}=958) \\
\end{array}$ & $\begin{array}{c}7.9 \\
(5.3-10.5) \\
\end{array}$ & $\begin{array}{c}2.13 \\
(1.22-3.03) \\
\end{array}$ & $\begin{array}{c}7.75 \\
(5.08-10.42) \\
\end{array}$ & $\begin{array}{c}3.09 \\
(1.74-4.44) \\
\end{array}$ & $\begin{array}{c}3.96 \\
(2.59-5.33) \\
\end{array}$ & $\begin{array}{c}3.33 \\
(2.01-4.64) \\
\end{array}$ & $\begin{array}{c}6.54 \\
(5.20-7.87) \\
\end{array}$ & $\begin{array}{c}2.85 \\
(2.17-3.52) \\
\end{array}$ \\
\hline & $\begin{array}{c}2006-7 \\
(\mathrm{~N}=808)\end{array}$ & $\begin{array}{c}9.2 \\
(6.41-11.99) \\
\end{array}$ & $\begin{array}{c}1.20 \\
(0.75-1.66)\end{array}$ & $\begin{array}{c}9.71 \\
(6.62-12.79) \\
\end{array}$ & $\begin{array}{c}1.79 \\
(1.01-5.57)\end{array}$ & $\begin{array}{c}7.80 \\
(5.31-10.29)\end{array}$ & $\begin{array}{c}3.42 \\
(1.95-4.90)\end{array}$ & $\begin{array}{c}8.90 \\
(7.36-10.45)\end{array}$ & $\begin{array}{c}2.14 \\
(1.55-2.73) \\
\end{array}$ \\
\hline & $\begin{array}{l}2007-8 \\
(N=911)\end{array}$ & $\begin{array}{c}11.94 \\
(7.87-16.01) \\
\end{array}$ & $\begin{array}{c}1.07 \\
(0.62-1.52) \\
\end{array}$ & $\begin{array}{c}11.66 \\
(7.78-15.54) \\
\end{array}$ & $\begin{array}{c}1.35 \\
(0.85-1.86) \\
\end{array}$ & $\begin{array}{c}8.67 \\
(5.93-11.40) \\
\end{array}$ & $\begin{array}{c}2.8 \\
(1.62-3.99) \\
\end{array}$ & $\begin{array}{c}10.76 \\
(8.74-12.44) \\
\end{array}$ & $\begin{array}{c}1.74 \\
(1.27-2.21) \\
\end{array}$ \\
\hline & $\begin{array}{c}2008-9 \\
(\mathrm{~N}=829)\end{array}$ & $\begin{array}{c}14.03 \\
(9.33-18.72)\end{array}$ & $\begin{array}{c}1.02 \\
(0.6-1.45)\end{array}$ & $\begin{array}{c}14.16 \\
(9.18-19.13)\end{array}$ & $\begin{array}{c}1.17 \\
(0.72-1.62)\end{array}$ & $\begin{array}{c}11.78 \\
(7.72-15.83)\end{array}$ & $\begin{array}{c}1.68 \\
(0.98-2.37)\end{array}$ & $\begin{array}{c}13.32 \\
(10.79-15.85)\end{array}$ & $\begin{array}{c}1.29 \\
(0.99-1.59)\end{array}$ \\
\hline
\end{tabular}

$\mathrm{Cl}$ : confidence interval; GP: general practitioner.

${ }^{1}$ April to March of following year. 
reporting units over time. Between 396 and 518 pediatricians and 156 to $275 \mathrm{GPs}$ reported per month to the sentinel and the respective number of reporting units per season ranged from 499 to 635 pediatricians and 260 to $381 \mathrm{GPs}$. The mean response rate was $76 \%$ for paediatricians and $54 \%$ for GPs and was stable in both groups over time. However, the proportion of paediatric units among all reporting units declined slightly from about $66 \%$ in the seasons $2005-6$ and $2006-7$ to about $60 \%$ in 2007-8 and 2008-9 (Figure 1; Table 1).

The number of monthly reported varicella cases per unit in all age groups together decreased from varicella season 1 to season 4 from 2.85 to 1.29 , which

\section{FIGURE 2}

Average number of varicella cases per month and reporting unit by age over four varicella seasons, sentinel data, Germany, April 2005-March 2009

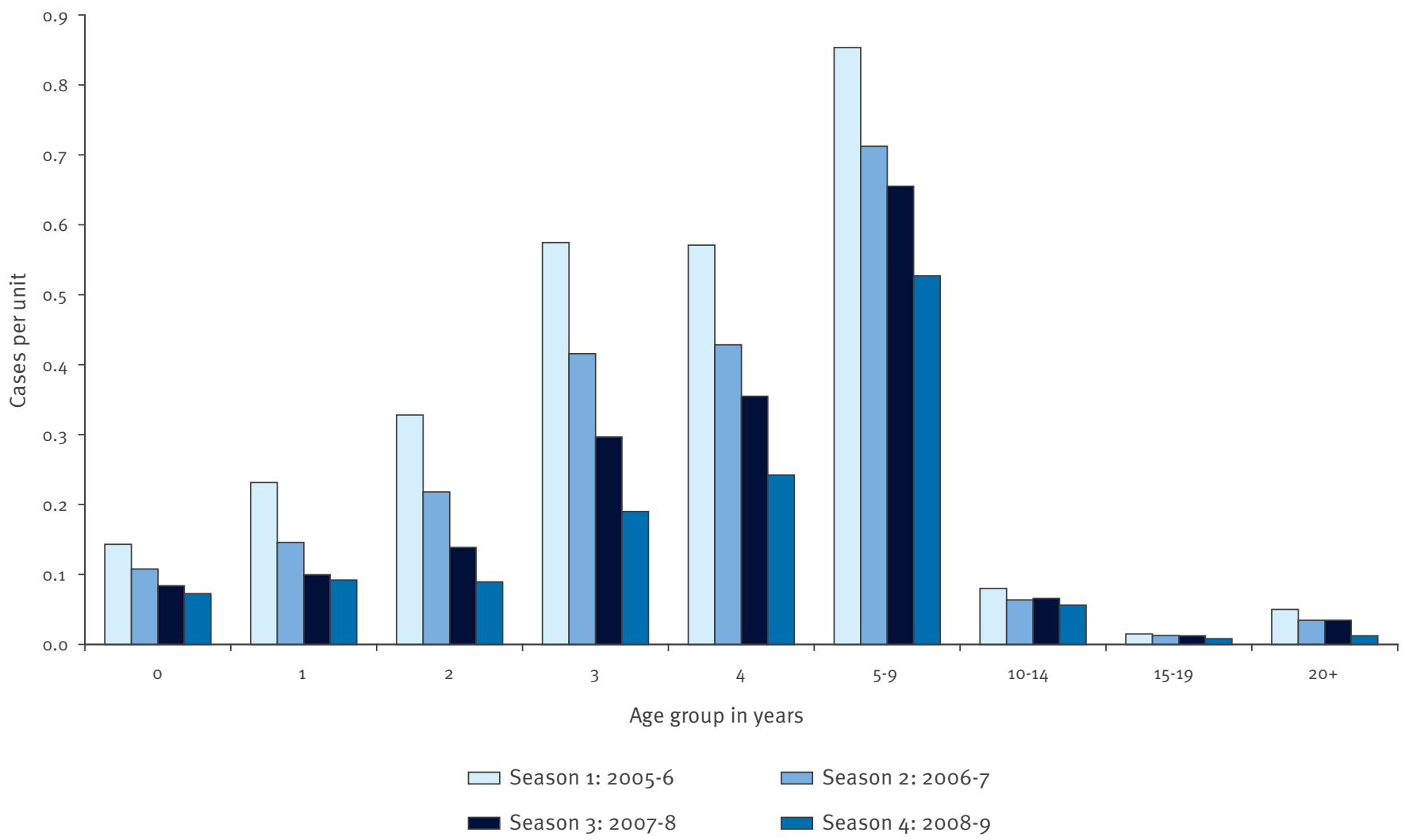

\section{TABLE 2}

Total number of administered varicella vaccines as first and second, monovalent and combined doses and numbers per reporting unit by season and physician group, sentinel data, Germany, April 2005-March 2009

\begin{tabular}{|c|c|c|c|c|c|c|c|c|}
\hline \multirow[b]{2}{*}{ Season $^{1}$} & \multicolumn{4}{|c|}{ Paediatricians } & \multicolumn{4}{|c|}{ General practitioners } \\
\hline & $\begin{array}{c}\text { 1st dose } \\
\text { monovalent } \\
\text { varicella vaccince } \\
\text { (n per unit) }\end{array}$ & $\begin{array}{c}\text { 1st dose } \\
\text { MMRV } \\
\text { (n per unit) }\end{array}$ & $\begin{array}{c}\text { 2nd dose } \\
\text { monovalent } \\
\text { varicella vaccince } \\
\text { (n per unit) }\end{array}$ & $\begin{array}{l}\text { 2nd dose } \\
\text { MMRV } \\
\text { (n per unit) }\end{array}$ & $\begin{array}{c}\text { 1st dose } \\
\text { monovalent } \\
\text { varicella vaccince } \\
\text { (n per unit) }\end{array}$ & $\begin{array}{c}\text { 1st dose } \\
\text { MMRV } \\
\text { (n per unit) }\end{array}$ & $\begin{array}{c}\text { 2nd dose } \\
\text { monovalent } \\
\text { varicella vaccince } \\
\text { (n per unit) }\end{array}$ & $\begin{array}{c}\text { 2nd dose } \\
\text { MMRV } \\
\text { (n per unit) }\end{array}$ \\
\hline \multirow{2}{*}{$2005-6$} & 64,203 & & 1,914 & & 1,657 & & 218 & \\
\hline & $(106.8)$ & & $(3.2)$ & & $(6.3)$ & & $(0.8)$ & \\
\hline \multirow{2}{*}{$2006-7^{2}$} & 75,493 & & 7,369 & & 2,308 & & 439 & \\
\hline & (143.8) & & $(14.0)$ & & $(10.6)$ & & $(2.0)$ & \\
\hline \multirow{2}{*}{$2007-8$} & 29,656 & 42,771 & 2,792 & 22,901 & 961 & 1,371 & 308 & 1,153 \\
\hline & (59.6) & $(85.6)$ & $(5.6)$ & $(46.0)$ & (3.8) & $(5.4)$ & $(1.2)$ & $(4.5)$ \\
\hline \multirow{2}{*}{$2008-9$} & 19,635 & 49,305 & 13,759 & 33,928 & 546 & 1,421 & 372 & 1,241 \\
\hline & (41.3) & & $(29.0)$ & $(71.4)$ & $(2.4)$ & $(6.2)$ & $(1.6)$ & $(5.4)$ \\
\hline
\end{tabular}

MMRV: measles-mumps-rubella-varicella vaccine.

1 April to March of following year.

2 As MMRV was available since summer 2006 but reporting of MMRV-doses started in April 2007, an undefined no. of MMRV doses may be included in this season. 
is a reduction of $55 \%$ of cases. In the age group 0-4 years cases per month and unit declined from 1.85 to $0.69(63 \%)$, and in the 5 -9-year-olds from 0.85 to 0.53 (38\%). A reduction was also observed in the age group 20 years and older. However, only $1 \%(n=784)$ of all reported cases belonged to this age group and a reduction from 0.05 to 0.01 (75\%) was observed between varicella season 1 and 4 (Figure 2). In all varicella seasons the majority of cases occurred in 0-4 year-olds. Proportions between age groups shifted over time; in season $1,65 \%$ of all cases were seen in $0-4$ year-olds and $30 \%$ in $5-9$ year-olds, whereas the proportions were $53 \%$ and $41 \%$ respectively in season 4 .

\section{Cases and vaccinations by reporting} units and cost cover groups

The number of cases and administered vaccines per reporting unit and month differed by physician group and region; in all regions paediatricians administered six to eight times more varicella vaccines and saw seven to nine times more varicella cases than GPs (Table 1). The total number of varicella cases per season $(n=32,569 ; 21,384 ; 16,846$ and 12,414 in varicella seasons $1,2,3$ and 4 respectively) as well as the mean number of cases per reporting unit and month decreased steadily over the four seasons. This trend was seen in case reports by both physician groups in all regions together and by GPs alone in each of the three regions, for paediatricians this trend was also found in regions 1 and 2 but not region 3 (Table 1 ). In all four seasons, in region 1 (region with earliest cost regulation) all units together had less varicella cases per unit and month on average than in the other two regions; the highest number of cases per month was reported by paediatricians and GPs from region 3 (region, were cost regulation was settled last). The greatest difference in case reports between region 3 and the other two regions was calculated for seasons 2 and 3 in both physician groups. In the paediatric units of region 1 a decrease of cases per unit was seen in season 2 compared with season 1 , and values remained stable on a low level in the following two seasons. In the GP units of region 1 the case numbers decreased over all four seasons but to a lesser extent than in the paediatrician group. A decrease over four seasons was also observed for both physician groups in region 2 with the above described differences between paediatricians and GPs and starting from a lower level than in region 1. However, in region 3 a remarkable decrease in cases per paediatric units did not start until season 4 and for GP units until season 3.

In all four varicella seasons, paediatricians and GPs from region 1 and 2 administered more varicella doses than those from region 3 , but this difference was most prominent in season 1.

\section{Vaccinations by physician groups over time} With 281,063 first and 82,663 second doses, $97 \%$ of all varicella vaccine doses were administered by paediatricians (Table 2). The number of first doses per paediatric reporting unit increased over three seasons and remained stable in season 4 . With $35 \%$, the increase was strongest from season 1 to 2 . The number of second doses per paediatric unit increased steadily over time from 3.2 in season 1 to 100.4 in season 4 . An increase in the total number of doses per unit was also seen in the GP group, however at lower level and divergent for first and second doses. Whereas first doses per unit increased from season 1 to season 2 and then slightly decreased over the following seasons, second doses per unit increased steadily over all four seasons. In season 3 less monovalent vaccine doses were administered per unit compared with season 2. This was partly balanced by the use of MMRV. The number of MMRV per unit exceeded by far the number of first and second doses of monovalent vaccine in both physician groups. Whereas MMRV vaccine use has contributed most to the increase of second doses since season 2 , there

\section{TABLE 3}

Number of vaccinated cases, cases with complications and with Herpes zoster by physician group and by season, sentinel data, Germany, April 2005-March 2009

\begin{tabular}{|c|c|c|c|c|c|c|}
\hline Season $^{1}$ & $\begin{array}{l}\text { Vaccinated } \\
\text { varicella cases, } \\
\text { reported by } \\
\text { paediatricians } \\
\text { (\% of all cases) }\end{array}$ & $\begin{array}{l}\text { Vaccinated } \\
\text { varicella cases, } \\
\text { reported by GPs } \\
\text { (\% of all cases) }\end{array}$ & $\begin{array}{l}\text { Complications, } \\
\text { reported by } \\
\text { paediatricians } \\
\text { (\% of all cases) }\end{array}$ & $\begin{array}{l}\text { Complications, } \\
\text { reported by GPs } \\
\text { (\% of all cases) }\end{array}$ & $\begin{array}{l}\text { Herpes zoster, } \\
\text { reported by } \\
\text { paediatrician } \\
\text { [cases per unit] }\end{array}$ & $\begin{array}{l}\text { Herpes zoster, } \\
\text { reported by GPs } \\
\text { [cases per unit] }\end{array}$ \\
\hline $2005-6$ & $\begin{array}{c}283 \\
(0.9) \\
\end{array}$ & $\begin{array}{c}6 \\
(0.4) \\
\end{array}$ & $\begin{array}{l}130 \\
(0.4) \\
\end{array}$ & $\begin{array}{c}12 \\
(0.7) \\
\end{array}$ & $\begin{array}{c}505 \\
{[0.8]}\end{array}$ & $\begin{array}{l}1,046 \\
{[3.2]} \\
\end{array}$ \\
\hline $2006-7$ & $\begin{array}{l}473 \\
(2.3) \\
\end{array}$ & $\begin{array}{c}9 \\
(0.8) \\
\end{array}$ & $\begin{array}{c}65 \\
(0.3) \\
\end{array}$ & $\begin{array}{c}12 \\
(1.0)\end{array}$ & $\begin{array}{l}495 \\
{[0.9]}\end{array}$ & $\begin{array}{l}1,035 \\
{[4.0]}\end{array}$ \\
\hline $2007-8$ & $\begin{array}{c}816 \\
(5.2) \\
\end{array}$ & $\begin{array}{c}32 \\
(2.9) \\
\end{array}$ & $\begin{array}{c}55 \\
(0.3) \\
\end{array}$ & $\begin{array}{c}10 \\
(0.9) \\
\end{array}$ & $\begin{array}{c}456 \\
{[0.9]} \\
\end{array}$ & $\begin{array}{l}1,100 \\
{[2.9]} \\
\end{array}$ \\
\hline $2008-9$ & $\begin{array}{l}988 \\
(8.5)\end{array}$ & $\begin{array}{c}28 \\
(3.4)\end{array}$ & $\begin{array}{c}20 \\
(0.2)\end{array}$ & $\begin{array}{c}6 \\
(0.7)\end{array}$ & $\begin{array}{c}423 \\
{[0.8]}\end{array}$ & $\begin{array}{c}1,083 \\
{[3.3]}\end{array}$ \\
\hline
\end{tabular}

GP: general practitioners.

April to March of following year. 
was also a remarkable increase of monovalent second doses per unit from season 3 to 4 .

\section{Other reporting categories}

The number of varicella in vaccinated persons increased from 289 in varicella season 1 to 1,016 in season 4 and the proportion of vaccinated on all reported varicella cases went up from 0.9 to $8.2 \%$. Although the upwards trend was seen by both physician groups, numbers and proportions of vaccinated patients were much higher in paediatricians reports in comparison to GPs (Table 3 ). The total number of reported complications went down from 142 cases ( $0.4 \%$ of all reported varicella cases) to $26(0.2 \%)$ over the four seasons and again this trend was more distinctive in paediatricians.

Concerning herpes zoster the crude reporting numbers in all four seasons were higher from GPs than from paediatricians corresponding to about four times more cases per reporting unit. However, a steady number of cases per unit were observed over time by both physician groups.

\section{Discussion}

Germany is one of the few countries worldwide where varicella vaccination has been introduced in the routine childhood vaccination schedule. The most prominent effects in the first four years after introduction of vaccination are the decrease in number of varicella cases and the increasing acceptance of vaccination [8]. Descriptive analysis of sentinel data provided evidence of a reduction in the number of cases in four consecutive seasons following the introduction of the vaccination programme. The decrease was greatest in $0-4$ year-olds, but the trend was seen in all age groups. Comparable results were reported from the US where after the introduction of varicella vaccination in the routine childhood vaccination programme in 1996 varicella incidence declined substantially between 1995 and 2000 in the sentinel regions [9].

The decrease in varicella morbidity in Germany can not be explained by secular trends. In absence of notification data this can be demonstrated by data from hospital discharges in the time from 1994 to 2004, the pre-vaccination era. The median of the annual number of hospitalised varicella cases was 1,957 and ranged from 1,806 cases in 2002 to 2,316 cases in 2004 [10]. In the three years after the general recommendation of varicella vaccination the annual number of hospitalised varicella cases steadily declined from 1,751 in 2005 to 1,269 in 2007 . The decline in number of hospitalised cases per 100,000 population was largest in the age group 1-4 years old (from $>20$ hospitalised varicella cases per 100,000 population in 1994-2004 to 10 in 2007) and in infants (30 in 1994-2004 to 21 in 2007). The decrease in varicella morbidity was observed in two independent sources and supported through comparison with data from the pre-vaccination era.

The rise in vaccine doses per reporting unit in all regions and all physician groups over the observed time period in the sentinel indicates an increased acceptance of varicella vaccination. Moreover, there are clear associations between reimbursements for vaccination and vaccine uptake on the one hand and the increase of vaccine uptake up to a stable level and the decrease of number of cases on the other. In the region were costs of vaccination were covered from the beginning of the programme the number of vaccines administered per physician were higher compared with the regions were reimbursement was settled at a later stage. The sentinel observations and descriptive statistics show, that when reimbursement was settled early and vaccine doses were increasing, the varicella cases started to decrease early as well. The time span between increasing number of vaccinations after cost regulations and the first visible effects on the number of varicella cases was about 1.5 seasons. Besides reimbursement policies the availability of vaccines and schedules of vaccination play an important role for vaccine uptake. While the increase of vaccinations in the first season after introduction of the programme was mainly due to negotiated reimbursement, the availability of MMRV has led to a growing number of second doses since autumn 2006. The administration of second varicella vaccine doses was further accelerated in the season four due to a change in the licensed vaccination schedule for monovalent varicella vaccines from one to two doses.

With increasing numbers of vaccinated persons, the number of patients with varicella has decreased over time in Germany. The reduction was greatest in the group targeted for vaccination, i.e. young children. The observed proportion shift in the number of varicella cases from 0-4 year-olds towards 5-9 year-old children is a result of the greater reduction of varicella disease in toddlers and pre-school-age children in comparison to school-age children. A shift in the disease rates as given by number of cases per age and reporting unit towards older age groups has not been observed in the four seasons in the sentinel. Thus, a shift towards older age groups, associated with a higher risk of complications from varicella disease, has not been observed until now. Moreover, our results show that the number of complications has declined in the sentinel.

With increasing numbers of vaccinated persons the potential for varicella disease in vaccinated persons is increasing and the proportion of vaccinated among all varicella cases will increase as well. This was shown in the US [13] and is now confirmed by the results of our sentinel surveillance in Germany. For further analysis case based data are necessary in order to differentiate between varicella shortly after vaccination and breakthrough cases. Case-based data are also necessary to investigate the reported cases of herpes zoster more thoroughly. So far no trend in the frequency of herpes zoster was detected in the sentinel.

As the sentinel system is not population based, incidence or vaccine coverage can not be estimated. For this purposes a notification system would be appropriate. 
Although passive reporting (as for instance by notifications) is known to underestimate the total number of cases more than active reporting (as for instance this sentinel), the population under surveillance is clearly defined. Incidence by age and region could only be estimated if the denominator is known as in population based surveillance. Moreover, with further decreasing case numbers the sensitivity of the existing sentinel system might decrease. Therefore surveillance has to be adopted and one possible way would for instance be the introduction of varicella into statutory notifications in Germany.

In conclusion we can state that the varicella morbidity has started to decline and we are progressing towards reducing varicella morbidity and the overall burden of disease which are the main aims of the vaccination programme. Sentinel surveillance provides valid data on trends in varicella and herpes zoster morbidity in Germany and the age distribution of varicella cases so far. Furthermore, the sentinel seems to be appropriate to generate hypotheses for further investigations. If notification of varicella can not be implemented in the future, additional epidemiological data are needed to confirm sentinel results at population level and changing the current sentinel structures could ensure reliable case detection in the next years.

\section{Acknowledgements}

The working group on measles and varicella (AGMV) is a joint initiative of the Robert Koch Institute, the vaccine manufacturers Glaxo SmithKline and Sanofi Pasteur MSD and the German Green Cross. The vaccine manufacturers finance the work of the German Green Cross, whereas the Robert Koch Institute has not received any funding from the manufacturers.

We would like to thank the sentinel physicians for their efforts and continuous reports to the varicella sentinel. Moreover we thank the colleagues from the German Green Cross for data collection and data submission. We are grateful to Miriam Wiese-Posselt from the Immunisation unit at the Department of Infectious Disease Epidemiology at RKI and Rüdiger von Kries, the head of the scientific board of the AGMV, for their expert consultations. We also acknowledge Marion Muehlen, who contributed to case definitions and standard operating procedures for the participating physicians at the beginning of the sentinel.
5. Wagenpfeil S, Neiss A, Banz K, Wutzler P: Empirical data on the varicella situation in Germany for vaccination decisions. Clin Microbiol Infect. 2004;10(5):425-30

6. Lebensphasenspezifische Gesundheit von Kindern und Jugendlichen in Deutschland. Ergebnisse des Nationalen Kinder- und Jugendgesundheitssurveys (KiGGS). [Lifephase specific health of children and adoclecents in Germany. Results from the national survey on health of childern and adocecents.] Berlin: Robert Koch Institute; 2008:62-63

7. Arbeitsgemeinschaft Masern und Varizellen (AGMV). [Working group on measles and varicella.] [Internet]. Marburg, Germany. Available from: www.agmv.de

8. Robert Koch Institute. Zur Sentinel-Surveillance der Varizellen in Deutschland. [Regarding the sentinal surveillance of varicella in Germany]. Epid Bull. 2008;8;61-4

9. Guris D, Jumaan AO, Mascola L, Watson BM, Zhang JX, Chaves SS, et al. Changing varicella epidemiology in active surveillance sites - United States. 1995-2005. J Infect Dis. 2008;197 Suppl 2:S71-5

10. Das Informationssystem der Gesundheitsberichterstattung des Bundes. [The information system of the German Federal Bureau of Statistics]. [Internet]. Berlin, Germany. Available from: www. gbe-bund.de

11. Seward JF, Marin M, Vázquez M. Varicella vaccine effectiveness in the US vaccination program: a review. J Infect Dis. 2008;197 Suppl 2:S82-9

12. Bayer 0 , Heininger U, Heiligensetzer C, von Kries R. Metaanalysis of vaccine effectiveness in varicella outbreaks. Vaccine. 2007;25(37-38):6655-60

13. Chaves SS, Zhang J, Civen R, Watson BM, Carbajal T, Perella $D$, et al. Varicella disease among vaccinated persons: clinical and epidemiological characteristics, 1997-2005. J Infect Dis. 2008;197 Suppl 2:S127-31

\section{References}

1. Robert Koch Institute. Empfehlungen der Ständigen Impfkommission am Robert Koch-Institut/Stand Juli 2004. [Recommendation of the Standing Vaccination Commission (STIKO) at the Robert Koch Institute]. Epid Bull. 2004;30:235-50

2. Robert Koch-Institut. Begründung der STIKO für eine allgemeine Varizellenimpfung. [Statement of the Standing Vaccination Commission (STIKO) for the recommendation of the introduction of varicella vaccination.] Epid Bull. 2004;49: 421-3

3. Centers for Disease Control and Prevention. Prevention of varicella: recommendations of the Advisory Committee on Immunization Practices (ACIP). MMWR Recomm Rep. 1996;45(RR-11):1-36. Available from: www.cdc.gov/mmwr/ preview/mmwrhtml/00042990.htm

4. Centers for Disease Control and Prevention. Decline in annua incidence of varicella - selected states, 1990-2201. MMWR Morb Mortal Wkly Rep. 2003;52(37):884-5. Available from: http://www.cdc.gov/mmwr/preview/mmwrhtml/mm5237a2.htm 